\title{
Canada's National Advisory Committee on Immunization: Celebrating 50 years
}

\author{
Shalini Desai MD MHSc FRCP $(C)^{1}$, Shainoor J Ismail MD MSc FRCP $(C)^{2}$, \\ Robert Lerch RN BScN MSc ${ }^{3}$, Bryna F Warshawsky MD CCFP ${ }^{4}$, lan Gemmill MD CCFP?
}

\begin{abstract}
S Desai, SJ 1smail, R Lerch, BF Warshawsky, I Gemmill. Canada's National Advisory Committee on Immunization: Celebrating 50 years. Can J Infect Dis Med Microbiol 2015;26(3):126-128.
\end{abstract}

Vaccines have saved more lives than any other innovation in modern medicine. National immunization committees play a vital role in the development of evidence-based recommendations for the use of vaccines. The present article describes the evolution and work of the National Advisory Committee on Immunization in Canada as the group marks its 50th anniversary. The article also provides insight into the future challenges that the committee is likely to face.

Key Words: Advisory committee; Canada; Decision making; Immunization programs

$\mathrm{O}$ ften referred to as a modern miracle, vaccines are one of the most important public health measures (1), having saved more lives than any other innovation in modern medicine (2). Vaccine knowledge and development have advanced significantly since the first inoculation against smallpox in 1796. With rapid advances in vaccine development in the 1960s (including polio, measles, mumps and rubella vaccines [3]) came the creation of the National Advisory Committee on Immunizing Agents in Canada in the fall of 1964. This event marked the beginning of a long history of coordinated, expert advice on vaccines in this country. In honour of the 50th anniversary of the creation of what is now referred to as the National Advisory Committee on Immunization (NACI), the present article highlights the history and successes of this highly regarded committee, and discusses future challenges.

\section{THE HISTORY OF NACI}

The National Advisory Committee on Immunizing Agents was initially established in 1964 with a mandate to provide advice on immunizing agents to the Department of National Health and Welfare, and to make recommendations on immunizing agents that appeared to warrant special consideration to the Dominion Council of Health. In 1975, the mandate was revised to focus on advice related to the introduction of new vaccines in Canada and to assist in the development of immunization programs. In 1978, the name of the committee was changed to the National Advisory Committee on Immunization, reflecting the revised mandate for consideration of procedures related to immunization and immunization coverage.

Over the years, NACI has evolved from providing advice on only a few vaccines to now providing technical guidance for $>50$ different authorized vaccine products to prevent 24 different diseases (4). NACI is a highly regarded scientific advisory committee that has been recognized

\section{Le Comité consultatif national de l'immunisation du Canada : 50 ans à célébrer}

Les vaccins ont sauvé plus de vies que n'importe quelle autre innovation de la médecine moderne. Les comités nationaux d'immunisation jouent un rôle essentiel dans la préparation de recommandations fondées sur des données probantes relatives à l'utilisation des vaccins. Le présent article décrit l'évolution et le travail du Comité consultatif national de l'immunisation du Canada, qui célèbre son cinquantième anniversaire. Il contient également un aperçu des prochains défis que le comité devra probablement relever.

\begin{abstract}
globally as one of 15 "well-established National Immunization Technical Advisory Groups" (5) that can be regarded as a resource in establishing similar groups in other countries to enhance the use of evidence-based decision-making processes in the development of immunization programs and policies. In Canada, the National Advisor on Healthy Children and Youth has recognized the importance of the work of $\mathrm{NACI}$, and recommended that "the federal government continue to support the work of the National Advisory (Committee) on Immunization (NACI) in getting valuable information to health care providers and parents" (6).
\end{abstract}

\section{THE PEOPLE AND THE PROCESS}

The current mandate of NACI is to provide the Public Health Agency of Canada (PHAC) with ongoing and timely medical, scientific and public health advice related to vaccines and certain immunoglobulins for both adult and pediatric populations (7). This is accomplished through the efforts of appointed expert members, liaison representatives from organizations with an interest in immunizations and vaccines, as well as ex officio representatives from relevant areas of the federal government, and secretariat support through the Centre for Immunization and Respiratory Infectious Diseases (8). The vaccine industry provides valuable information to the committee related to products in development and ongoing clinical trials, but they do not participate in NACI's funding, its deliberations or in the development of its recommendations. Members are expected to express their personal opinions as informed by their professional expertise, experience and relevant evidence. Members are asked to submit conflict of interest declarations annually and provide updates as they arise. These declarations are assessed for impact on NACI deliberations and recommendations, with potential management strategies including limited participation on specific agenda items. The intent of the committee is

${ }^{1}$ Public Health Agency of Canada, Toronto, Ontario; ${ }^{2}$ Public Health Agency of Canada, Edmonton, Alberta; ${ }^{3}$ Public Health Agency of Canada,

Ottawa; ${ }^{4}$ Public Health Ontario, Toronto, Ontario

Correspondence: Dr Shalini Desai, Public Health Agency of Canada, 180 Queen Street West, Toronto, Ontario M5G 1V2.

Telephone 647-260-7431, e-mail shalini.desai@phac-aspc.gc.ca 
to ensure that unbiased expert advice, based on best practices and evidence, is provided to assist PHAC in informing the Canadian public health community and frontline providers.

As the committee has evolved, a scientific methodology and more transparent process have been embraced for making recommendations. A search of relevant published data, along with grey literature, is conducted to understand the currently available information regarding vaccine efficacy, effectiveness, immunogenicity and safety. Cost and cost-effectiveness is not currently considered in NACI deliberations. The literature review is generally guided by a working group chairperson to ensure that all relevant data are reviewed. These data are then synthesized, along with a ranking of the level and quality of evidence. Canadian epidemiology, using a variety of published and unpublished sources, is used to understand the burden of disease and the potential for improving health at a population level for a particular disease. The committee then 'puts it all together' by reviewing the benefits and risks, following which the evidence is translated into scientifically grounded recommendations (9).

\section{KNOWLEDGE TRANSLATION}

Once NACI has made its recommendations, several products are developed to ensure that they are available to a variety of stakeholders. NACl's recommendations can be found in the Canadian Immunization Guide (4) (the Guide), in advisory committee statements and in detailed literature reviews (7). These materials are made available on PHAC's website (www.phac-aspc.gc.ca/naci-ccni/index-eng.php\#rec).

The Guide is intended to support the front-line immunizer in providing the right vaccine at the right time to the right person via the right route and at the right dose. It also assists health care professionals in responding to questions from potential vaccine recipients or their caregivers, including providing current knowledge regarding vaccine safety. In 2014, the Guide has been moved from its traditional book format to an Internet-based 'ever-green' format. This change allows for timely updating of information and improvements in providers' ability to obtain the most accurate information.

Advisory committee statements provide details of the Canadian epidemiology related to the disease under consideration, an overview of the efficacy, effectiveness, immunogenicity and safety of a particular vaccine, and a summary of NACI's recommendations for the use of that vaccine. More details regarding the literature review that was conducted to support the development of the statement and its recommendations are often published separately. The literature review, the advisory statement or both contain detailed tables summarizing and assessing each individual study that was considered.

The number of advisory committee statements written annually has increased over the years, reflecting the increase in the number, complexity and specific indications for use of vaccine products. For example, NACI issues an annual influenza statement. Each year, this statement provides an overview of the epidemiology from the previous year's influenza season and a summary of the vaccines available in Canada for the upcoming influenza season, along with

\section{REFERENCES}

1. Ehreth J. The global value of vaccination. Vaccine 2003;21:596-600.

2. How vaccination saves lives. United Kingdom: National Health Service, 2014 (updated April 4 2014). <www.nhs.uk/conditions/vaccinations/ pages/vaccination-saves-lives.aspx> (Accessed October 14, 2014).

3. Taking shots: The modern miracle of vaccines. Medscape Pediatrics, 2004 (updated June 24, 2004). <www.medscape.com/ viewarticle/481059> (Accessed October 14, 2014).

4. Canadian immunization guide. Ottawa: Public Health Agency of Canada; 2014 (updated April 23, 2014). <www.phac-aspc.gc.ca/ publicat/cig-gci/index-eng.php $>$ (Accessed October 14, 2014).

5. Gessener B, Duclos P, DeRoeck D, Nelson E. Informing decision makers: Experience and process of 15 national immunization technical advisory groups. Vaccine 2010;28(S1):1-5.

6. Leitch K. Reaching for the top: A report by the advisor on healthy children and youth. Ottawa: Health Canada, 2007. Report No.:978-0-662-46456-3. their recommended usage. Recent updates to the influenza statement have included a change in the recommended pediatric dose for those six to 36 months of age from $0.25 \mathrm{~mL}$ to $0.5 \mathrm{~mL}$ (10), a preferential recommendation of live attenuated intranasal influenza vaccine for children two to six years of age (11), a recommendation for vaccination of egg-allergic individuals when this had previously been a contraindication (10) and the progressive expansion of the age indications for routine influenza vaccination, which is now recommended for everyone $\geq 6$ months of age $(12,13)$. Current issues being considered include the use of quadrivalent vaccines that provide protection against both lineages of influenza B and the possible preferential use of more efficacious vaccines in certain age groups. As new products, evidence and indications evolve, NACI revisits its recommendations to keep them up to date, relevant, and based on the best and most current evidence.

\section{FUTURE CHALLENGES}

Vaccine innovation and development is continuing at an impressive pace. Vaccine development pipelines contain candidate vaccines targeted not only against infectious diseases, but also to prevent chronic diseases. Vaccine technologies are also expanding, with the potential to prevent a range of diseases that have proved to be challenging to address with current technologies. As these new products come to market, there will be an increasing demand for rigorous, unbiased guidance to understand how they can be used to improve the health of Canadians.

NACI currently focuses on the epidemiology and the scientific aspects of a vaccine product. As the vaccine landscape becomes more complex, it may be necessary to expand this mandate to include other elements in the analysis and recommendations; for example, the feasibility and acceptability of a new vaccine, as well as the cost effectiveness and societal impact. Additional attention must also be devoted to vaccine program considerations including vaccine uptake, vaccine hesitancy, and surveillance systems to monitor vaccination programs and vaccine safety. Given this possible expanded mandate, it may be necessary to employ a different model of creating vaccine guidance and recommendations; however, it will continue to be essential to ensure that the processes used by NACI are systematic, rigorous, transparent, timely and unbiased.

\section{SUMMARY}

Over the past 50 years, NACI has contributed to the practice of immunization by providing thoughtful, practical and evidence-based guidance to individual vaccine providers, as well as to provinces and territories for their publically funded programs. NACI and PHAC, which supports NACI's work, recognize the importance of this work and are committed to continuing to provide this advice within the rapidly changing landscape of vaccine development and a possible evolving mandate of the committee. As it has been in the past 50 years, the advice of NACI will continue to be vital to supporting the future delivery and uptake of the modern miracle of vaccines.

7. National Advisory Committee on Immunization. Ottawa: Public Health Agency of Canada, 2014 (updated May 16, 2014). <www.phacaspc.gc.ca/naci-ccni/index-eng.php $>$ (Accessed October 14, 2014).

8. Ismail S, Langley J, Harris T, Warshawsky B, Desai S, FarhangMehr M. Canada's National Advisory Committee on Immunization (NACI): Evidence-based decision-making on vaccines and immunization. Vaccine 2010;28(Suppl 1):58-63.

9. National Advisory Committee on Immunization. Evidence-based recommendations for immunization: Methods of the national advisory committee on immunization. CCDR 2009;35(ACS-1). $<$ www.phac-aspc.gc.ca/publicat/ccdr-rmtc/09vol35/acs-1/index-eng. php> (Accessed October 14, 2014).

10. National Advisory Committee on Immunization. Statement on seasonal influenza vaccine 2011-2012. CCDR 2011;38(ACS-5). $<$ www.phac-aspc.gc.ca/publicat/ccdr-rmtc/11vol37/acs-dcc-5/indexeng.php $>$ (Accessed October 14, 2014). 
11. National Advisory Committee on Immunization. Revised wording to the National Advisory Committee on Immunization (NACI) recommendation for live attenuated influenza vaccine (LAIV) in healthy children and adolescents 2-17 years of age. CCDR 2013;39(ACS-4). <www.phac-aspc.gc.ca/publicat/ccdr-rmtc/13vol39/ acs-dcc-4/index-eng.php> (Accessed October 14, 2014).

12. National Advisory Committee on Immunization. Statement on seasonal influenza vaccine for 2012-2013. CCDR. 2012;38(ACS-2).
$<$ www.phac-aspc.gc.ca/publicat/ccdr-rmtc/12vol38/acs-dcc-2/indexeng.php> (Accessed October 14, 2014).

13. Statement on seasonal influenza vaccine 2014-2015. Ottawa: Public Health Agency of Canada, 2014 (updated September 19, 2014). $<$ www.phac-aspc.gc.ca/naci-ccni/flu-grippe-eng.php> (Accessed October 14, 2014). 


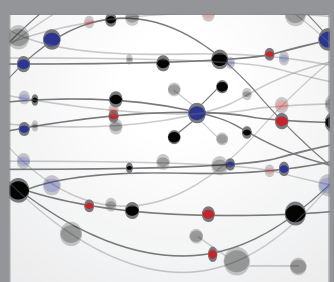

The Scientific World Journal
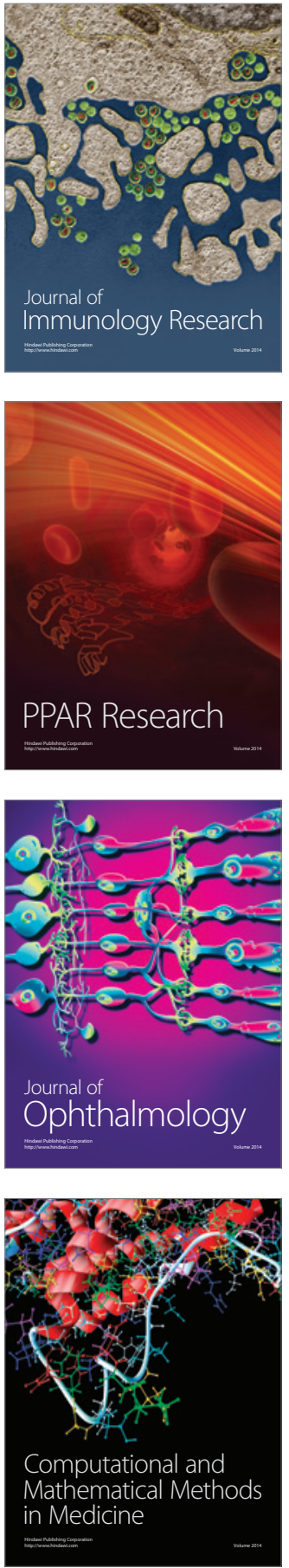

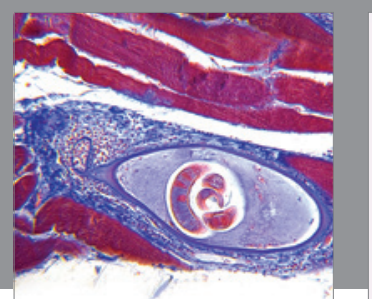

Gastroenterology Research and Practice

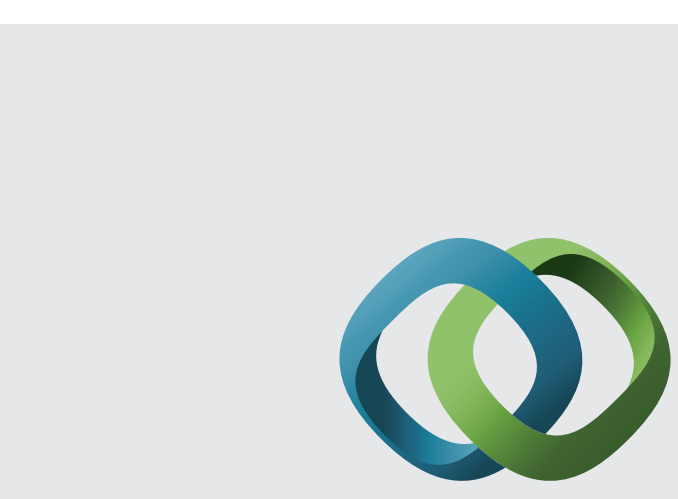

\section{Hindawi}

Submit your manuscripts at

http://www.hindawi.com
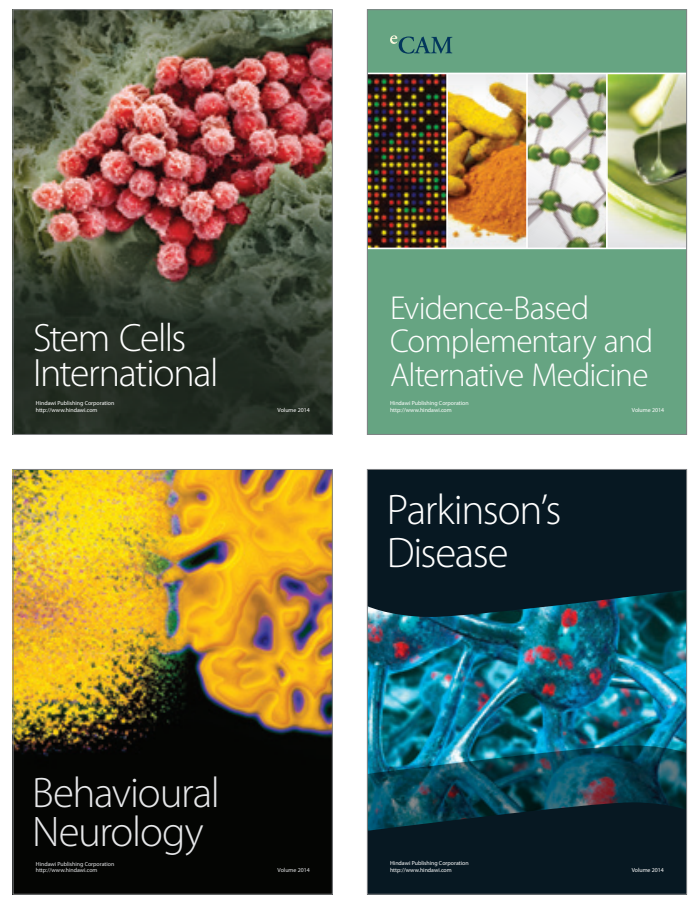
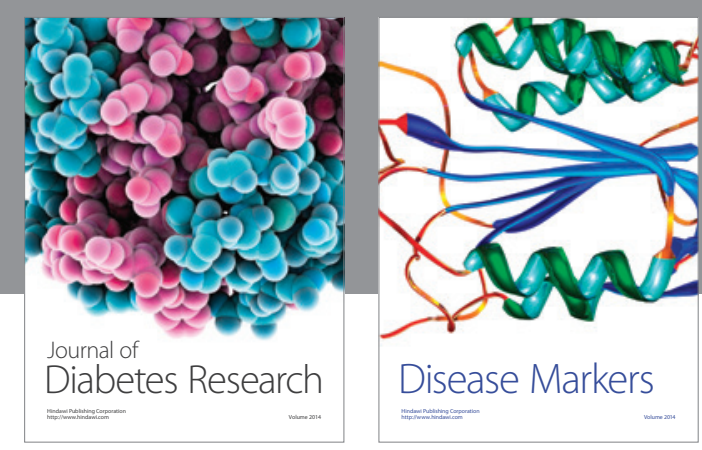

Disease Markers
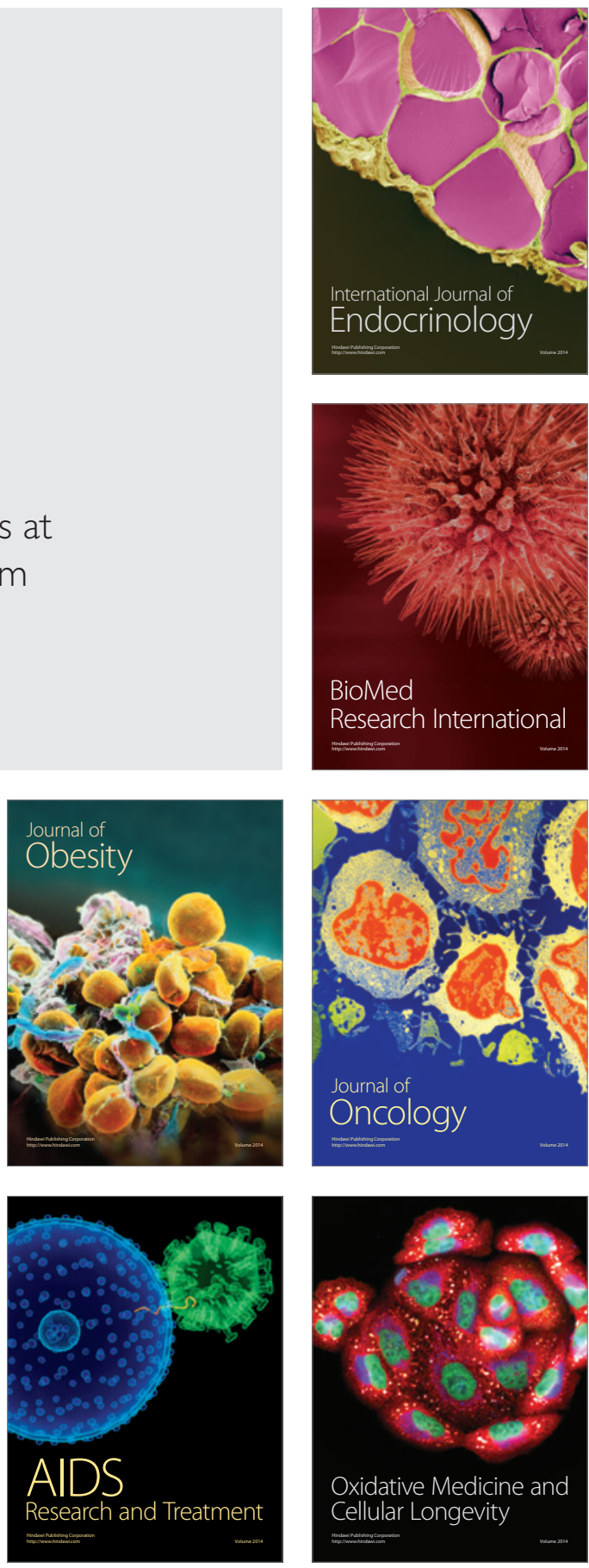